\title{
Team Based Learning in Pathology: Lessons Learned From a Pilot Study
}

\author{
Shruti Bhargava, ${ }^{1}$ Mohnish Grover, ${ }^{2}$ Neeraj Verma, ${ }^{1}$ Monica Jain ${ }^{3}$
}

\section{Abstract}

Background: Team based learning (TBL) is an approach where students are organised in groups where they learn from each other. TBL is a student centric approach, which ensures active participation of each member and also promotes teamwork and learning ability. Looking at the teacher centric approach of the conventional teaching learning methods in medical education, where the students are mere passive learners and the sessions can be monotonous, TBL seems to be extremely relevant today as a more student centric teaching learning method. Aim of this study was to compare TBL with conventional teaching learning method (CTL).

Methods: This randomised crossover study was conducted in the Department of Pathology, SMS Medical College, on 224 third semester medical students, wherein they were exposed to TBL session and their learning outcome and perception was compared to CTL. The data was analysed using Primer version 6 software.

Results: In this study, there was a statistically significant improvement $(\mathrm{p}<0.001)$ in the score of students after exposure to TBL. Also, there was a significant difference in the learning outcome of students of TBL (mean assessment score 7.21) as compared to CTL (mean assessment score 6.09). The student perception trends revealed a positive tilt towards TBL, wherein $70.98 \%$ students agreed that TBL was a better learning strategy as compared to lectures.

Conclusion: This pilot study concluded that TBL can be used as a supplement to the conventional lectures for improving the learning as well as team work and leadership skills of students.

Key words: Team based learning; Team work; Perception of students; Learning outcome.
(1) Department of Pathology, SMS Medical College, Jaipur, Rajasthan, India.

(2) Department of ENT, SMS Medical College, Jaipur, Rajasthan, India.

(3) Department of Pharmacology, SMS Medical College, Jaipur, Rajasthan, India.

Correspondence:

SHRUTI BHARGAVA

E: shrutibhargavapath@gmail.com

\section{ARTICLE INFO}

Received: 15 September 2021 Revision received: 28 September 2021 Accepted: 28 September 2021

\section{Introduction}

Team based learning (TBL) is an approach where the students are organised in groups where they learn from each other. ${ }^{1}$ Looking at the teacher-centric approach of the conventional teaching/ learning methods in medical education, where the students are mere passive learners and the sessions can be monotonous, today the need for a more student-centric teaching learning method is felt by all. TBL is a student centric approach, which ensures active participation of each member and also promotes teamwork and learning ability. ${ }^{2,3}$

Pathology is one of the most important subjects taught in second year in Indian medical schools and is the basis of medicine later on. It is a vast subject which requires in depth knowledge by the students to be able to solve problem-based scenarios, which can be successfully dealt with a 
team-based approach, as emphasised by previous authors. ${ }^{1}$

The traditional method of teaching can be improved by introducing the TBL approach for better learning and outcome. ${ }^{4,5}$ TBL is a cost-effective teaching learning method which uses the principle of small group learning to a class comprised of large number of students. ${ }^{5}$ This method requires just one teacher to manage multiple groups simultaneously in a large classroom setting. ${ }^{6}$

TBL uses strategies that ensure the effectiveness of small groups working independently with high student-to-faculty ratios, without losing the benefits of faculty-led small groups. ${ }^{6}$ It also enables the students to have profound insights into their strengths and weaknesses and thus become more self-directed in learning. ${ }^{5}$ This innovation generates interest in learning in students, increases interaction, team work, develop better communication skills as well as improve the overall learning ability of the students. ${ }^{5}$

The objective of this study was to introduce the concept of TBL in Pathology and evaluate the perception of students regarding this innovative teaching learning method and then compare the learning outcome of students exposed to TBL versus conventional teaching learning method (CTL).

\section{Methods}

This randomised crossover study for TBL was conducted at SMS Medical College in the Department of Pathology for third semester (II MBBS) students, of the academic year 2018-19, after obtaining approval from the Institutional Ethics Committee. Two sessions were conducted of 2-hour duration each, as shown in Figure 1.

\section{First session}

For the first session, at the onset, all third semester students were given a week's time to read the topic of thromboembolism, as a pre-class preparation. Then, on the day of the first session, all students who were present and gave informed consent were randomly divided into two groups (Group A - TBL and Group B - CTL) by chit box method.

Group A (TBL) was taken for TBL session for thromboembolism. This began with a pre-test of

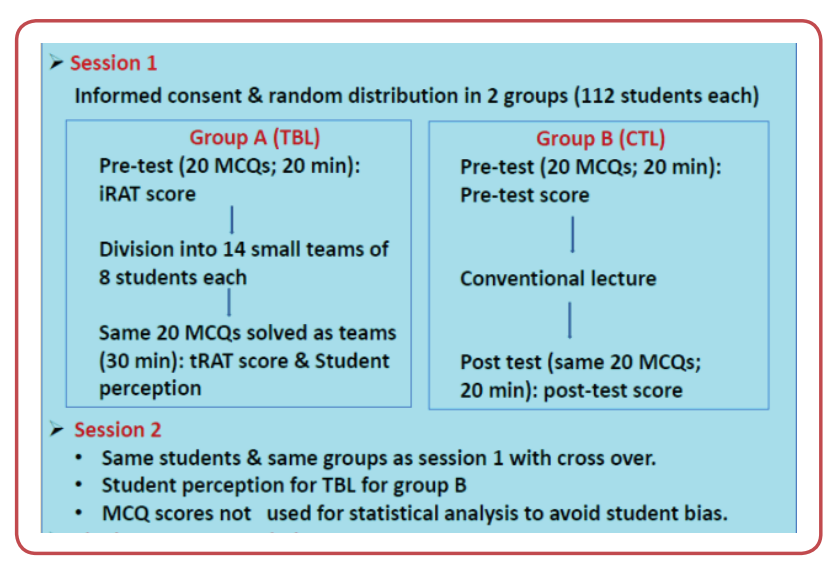

Figure 1: Workflow of team based learning (TBL) sessions CTL: conventional teaching learning; TBL: Team based learning; tRAT: team readiness assurance test; iRAT: individual readiness assurance test;

20 multiple choice questions (MCQs), which the students solved individually, within 20 minutes.

After their responses were collected, all the students were divided into 14 teams, each having 8 students. Now each of these 14 teams were given the same set of MCQs for solving, together as a group, within the next $30 \mathrm{~min}$. During this time, team members were encouraged to collaborate, discuss and reach a consensus. While this team test was in progress, the individual pre-test responses were evaluated, with each correct answer scoring 0.5 (the total score being 10), and this was called individual readiness assurance (iRAT) score.

Once all the 14 teams had completed their group test, each was provided with four different coloured placards each, showing responses/options namely A (red), B (green), C (yellow) and D (blue). The facilitator posed the given MCQs one by one and all teams were told to respond by raising the placard corresponding to their answer simultaneously (to avoid cheating). These scores of all the teams were recorded and called the team readiness assurance test (tRAT) score.

Thus, all 8 members of one particular team had same tRAT score. During this activity, the teacher also acted as a facilitator and cleared the doubts of these student groups. When the correct answers were provided by the instructor, teams that did not agree were allowed to appeal and the facilitators immediately clarified any misconceptions regarding their answers. After the session the students were given a pre-validated questionnaire to find out their perception for this new innovative teaching learning method, using a 5-point Likert scale. 
Simultaneously in a second classroom, group B (CTL) was taken for a conventional lecture for thromboembolism. For this, as with the TBL group, the students were individually given a pretest of same 20 MCQs initially. After 20 minutes, their responses were collected. Then, a faculty took a conventional lecture on thromboembolism for $30 \mathrm{~min}$. After the lecture the students were again individually given the same set of MCQs for solving (post-test) in $20 \mathrm{~min}$. Their pre-test and post-test scores were recorded.

\section{Second session}

After one week, the second session was conducted on the same students who participated in the first session and the students who were absent during this second session were excluded from the study. The group A of first session (TBL group) was crossed over with the group B of first session (CTL group). Thus, group A was exposed to CTL and group B to TBL. The topic covered this time was shock. Similar procedure was followed, as in session 1. However, the MCQ scores from this session were not used for statistical analysis to avoid students bias, although, the student perception was included in the final analysis in the study.

Comparison of the learning outcomes of TBL and CTL was done after the first session only, in the form of:

a) Intra-group (group A - TBL group) - The iRAT and tRAT scores of group A (TBL) were compared using paired t-test.

b) Intra-group (group B - CTL group) - the pretest and post-test scores of group B (CTL) were compared using paired t-test.

c) Inter-group (group A and B) - the tRAT score of group A (TBL group) was compared to the post-test score of group B (CTL group) using unpaired t-test.

The data was analysed using the Primer Version 6 software. The data analysis included percentage and proportion and a $p$ value of $<0.05$ was considered significant.

\section{Results}

Out of the total 250 students enrolled in the course, 224 students participated in this study and were randomly distributed into two groups, namely group A and group B, comprising of 112 students each. The rest of the students were excluded as they were absent during one or the other session.

On comparing the iRAT scores and tRAT scores of group A (TBL) students, it was found that the mean score of students significantly increased from $3.70 \pm 1.84$ to $7.21 \pm 0.86$ after the TBL session $(\mathrm{p}<0.001)$ (Figure 2).

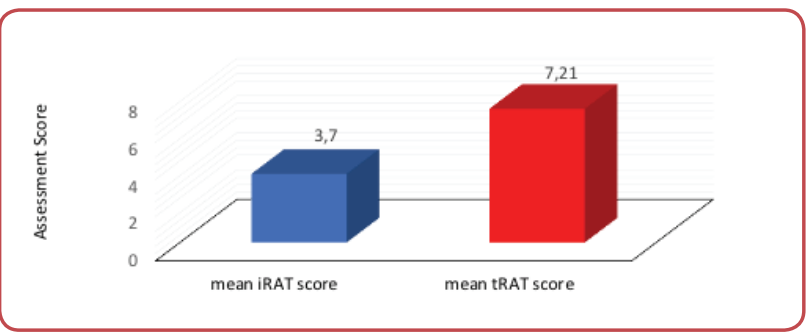

Figure 2: Comparison of mean iRAT and tRAT score of Group $A-T B L(n=112)$

TBL: Team based learning; iRAT: individual readiness assurance test; tRAT: team readiness assurance test;

On comparing the pre-test and post-test score of group B (CTL) students, who were exposed to the conventional lecture, it was observed that the mean score of students significantly increased from $3.59 \pm 1.92$ to $6.09 \pm 1.65$ after the lecture $(\mathrm{p}<0.001)$ (Figure 3).

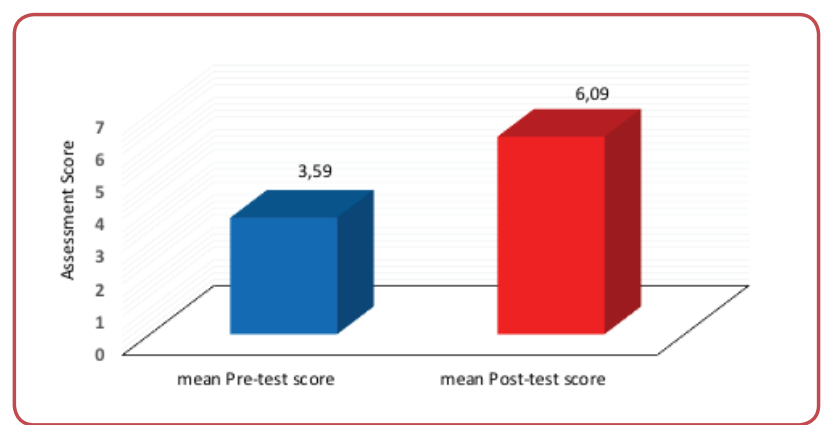

Figure 3: Comparison of pre-test and post-test score of Group $B-C T L(n=112)$

CTL: conventional teaching learning;

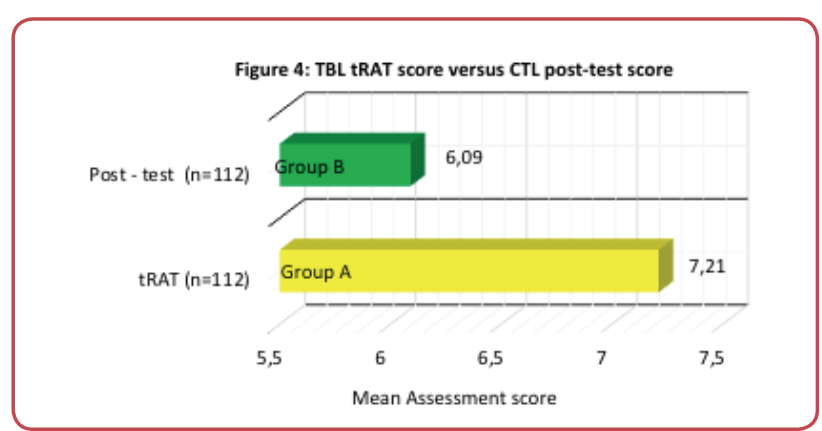

Figure 4: Comparison of final scores of both groups CTL: conventional teaching learning; TBL: Team based learning; tRAT: team readiness assurance test; 
Table 1: Perception of students of team based learning (TBL) $(n=224)$

\begin{tabular}{|c|c|c|c|c|c|}
\hline Question & $\begin{array}{l}\text { Score 1: strongly } \\
\text { disagree N (\%) }\end{array}$ & $\begin{array}{c}\text { Score 2: disagree } \\
\text { N (\%) }\end{array}$ & $\begin{array}{l}\text { Score 3: neutral } \\
\qquad \mathrm{N}(\%)\end{array}$ & $\begin{array}{c}\text { Score 4: agree } \\
\quad \mathrm{N}(\%)\end{array}$ & $\begin{array}{l}\text { Score 5: strongly } \\
\text { agree } \mathrm{N}(\%)\end{array}$ \\
\hline $\begin{array}{l}\text { TBL was better learning strategy as } \\
\text { compared to lecture }\end{array}$ & $1(0.45)$ & $1(0.45)$ & $21(9.38)$ & $42(18.75)$ & $159(70.98)$ \\
\hline $\begin{array}{l}\text { TBL was more effective in achieving } \\
\text { learning objectives }\end{array}$ & $1(0.45)$ & $2(0.89)$ & $18(8.04)$ & $54(24.1)$ & $149(66.5)$ \\
\hline $\begin{array}{l}\text { I was more focussed during TBL as } \\
\text { compared to lecture }\end{array}$ & 0 & $1(0.45)$ & $35(15.60)$ & $37(16.52)$ & $151(67.41)$ \\
\hline $\begin{array}{l}\text { TBL method improved my motivation to } \\
\text { learn }\end{array}$ & $1(0.45)$ & $3(1.34)$ & $29(12.95)$ & $28(12.50)$ & $163(72.77)$ \\
\hline $\begin{array}{l}\text { I think the knowledge I gained in TBL } \\
\text { session will be more permanent as } \\
\text { compared to lecture }\end{array}$ & $1(0.45)$ & $2(0.89)$ & $16(7.14)$ & $34(15.18)$ & $171(76.34)$ \\
\hline I enjoyed the TBL session & 0 & 0 & $15(6.7)$ & $35(15.63)$ & $174(77.68)$ \\
\hline $\begin{array}{l}\text { I have developed interpersonal and group } \\
\text { interaction skills }\end{array}$ & $1(0.45)$ & $3(1.34)$ & $19(8.49)$ & $44(19.65)$ & $157(70.09)$ \\
\hline $\begin{array}{l}\text { With TBL, I have gained profound in- } \\
\text { sights into my strengths and weaknesses } \\
\text { as a learner }\end{array}$ & $1(0.45)$ & $3(1.34)$ & $29(12.95)$ & $53(23.66)$ & $138(61.61)$ \\
\hline $\begin{array}{l}\text { TBL session has enabled me to develop } \\
\text { healthy personally rewarding relationship } \\
\text { with the teachers }\end{array}$ & $1(0.45)$ & $1(0.45)$ & $43(19.20)$ & $37(16.52)$ & $142(63.40)$ \\
\hline $\begin{array}{l}\text { I recommend more TBL sessions in } \\
\text { future }\end{array}$ & $1(0.45)$ & $1(0.45)$ & $11(4.91)$ & $34(15.18)$ & $177(79.02)$ \\
\hline
\end{tabular}

On comparing the tRAT score of group A (TBL) with the post test score of group B (CTL), it was found that the mean score of group A was more than that of group B, with a significant p-value (Figure 4). The final scores of students of both the groups increased from their respective pre-test scores, but the improvement was slightly more in the TBL group as compared to the CTL group.

The perception of students regarding TBL was taken as per the pre-validated feedback questionnaire comprising of ten questions and all the 224 students graded each question on a five-point Likert scale. (Table 1).

The findings clearly indicate the positive feedback of students about this innovation. As depicted, majority of the students (70.98 \%) totally agreed that TBL was a better learning strategy as compared to lectures, whereas $66.5 \%$ were in total agreement that TBL was more effective in achieving learning objectives. Most of the students were more focussed and motivated during the TBL session as compared to lectures, and also felt that the knowledge that they gained by TBL was likely to be more permanently retained.

Most of the students stated that the TBL session was an excellent opportunity for them to gain insight about their weaknesses and strengths and helped them to develop interpersonal skills as well as a good rapport with the facilitator. More than $77 \%$ students thoroughly enjoyed the TBL session and have recommended the use of this innovative teaching learning method in future also.

\section{Discussion}

This pilot study reveals a statistically significant improvement in the learning of students after exposure to TBL, as indicated by an increase in the mean tRAT score as compared to their iRAT score. The studies by Alwahab et al, Brandler et al and Chhabra et al have also shown similar findings. ${ }^{1,3,5}$

score of students who were exposed to the conventional lecture, as compared to their pre-test score was found. This has also been documented by Du et al and Punja et al. ${ }^{2,4}$ So, the importance of lectures cannot be undermined and lectures cannot be totally replaced by TBL. 
of both the TBL and CTL groups increased from their respective pre-test scores, the improvement was slightly more in the TBL group as compared to the CTL group. This was also observed by previous researchers. ${ }^{6-11}$ Devi et al have concluded that the TBL actually helped the academically weaker students to succeed. ${ }^{8}$

Regarding the perception of students, this study infers that most of the students have a positive feedback for this innovative teaching learning method. Majority of the students totally agreed that TBL was a better learning strategy as compared to lectures and was more effective in achieving learning objectives. Most of the students were more focussed and motivated during the TBL session as compared to lectures and also felt that the knowledge that they gained by TBL was likely to be more permanently retained by them. Maximum students realised that the TBL session was an excellent opportunity for them to gain insight about their weaknesses and strengths and also helped them to develop interpersonal skills as well as a good rapport with the facilitator. Almost all the students thoroughly enjoyed the TBL session and have recommended the use of this innovative teaching learning method in future. These findings corroborate with almost all the previous authors except Frame et al, who have found an almost equal perception score for conventional lecture and TBL. ${ }^{12}$ Thus, a synergistic approach between TBL and traditional lectures should be followed and TBL should be used as a supplement to conventional lectures for improvement of students' performance, as mentioned by other researchers. ${ }^{4,7}$

There were few limitations of this study. Since this innovation required at least two hours for completion of each session, it would not be possible to conduct it in 1-hour lecture time allotted routinely, as per the presently laid undergraduate timetable.

Though there was a statistically significant documented short-term positive change in learning of undergraduate students exposed to TBL as compared to CTL in this pilot study, it is necessary to carry out more sessions to generate data before a final conclusion about a lasting improvement in learning outcome and change in behaviour can be authentically drawn. Also, since this study was conducted in one department only and for a sin- gle topic, it would be difficult to draw generalised conclusions about advantages, limitations and feasibility of TBL.

It is planned to carry out this pilot study further by having more sessions in pathology and further start this innovation in other departments as well. Through the Medical Education Unit, plan is to sensitise other Faculty departments regarding this innovative teaching learning method as well.

\section{Conclusion}

This preliminary study clearly reflects that TBL can be a better teaching learning method, as compared to conventional didactic lectures, wherein the principles of effective small group teaching can be easily applied to a large group of 250 undergraduates without needing too many teachers at one time. Improvement in the final scores indicate an increase in the learning of students. Trends in the student perception questionnaire very clearly point towards the fact that this method can be used to motivate students towards studies, learning communication skills and collaborating as teams as well as provide insight into its implementation further at a larger scale.

Also, since TBL requires fewer faculty members compared to other active learning strategies (eg, self-directed learning and problem-based learning), and because it promotes greater student accountability in learning, it could serve as a useful alternative to other active learning strategies.

The high student satisfaction as well as improvement in the learning outcome observed in this study implies that it is necessary to incorporate such newer innovations for better teaching learning in medical colleges. However, CTL cannot be totally replaced by TBL, but, a combination of TBL approach and CTL methods should be used to improve students learnings. 


\section{Conflict of interest}

None.

\section{References}

1. Alwahab A, Abdulqader S, Nugud A, Nugud S, Cyprian F, Shaikh AA, et al. Team-based learning in an undergraduate pathology curriculum and its effects on student performance. J Taibah Univ Med Sci 2018 Jun 27;13(5):496501.

2. Du B, Yang X. The effect of team-based learning on conventional pathology education to improve students' mastery of pathology. Int J High Educ 2017;6(3):12-20.

3. Brandler TC, Laser J, Williamson AK, Louie J, Esposito MJ. Team-based learning in a pathology residency training program. Am J Clin Pathol 2014 Jul;142(1):23-8.

4. Punja D, Kalludi SN, Pai KM, Rao RK, Dhar M. Team-based learning as a teaching strategy for first-year medical students. Australas Med J 2014 Dec 31;7(12):490-9.

5. Chhabra N, Kukreja S, Chhabra S, Chhabra S, Khodabux S, Sabane H. Team-based learning strategy in biochemistry: perceptions and attitudes of Faculty and 1st-year medical students. Int J Appl Basic Med Res 2017 Dec;7(Suppl 1):S72-S77.

6. Hashmi NR. Team Based Learning (TBL) in undergraduate medical education. J Coll Physicians Surg Pak 2014 Aug;24(8):553-6.

\section{Acknowledgements}

None.

7. Ali AN, Elbayouk K, Osman A. Medical students' perspective on the place of team-based learning in the curriculum. Adv Med Educ Pract 2018 Oct 30;9:773-5.

8. Devi SR, Reddy CVM, Rao RP, Nagpal DKJ. Team Based Learning - A new approach for teaching pathology to medical students. Nat J Medical and Dental Research 2016;4(4):252-6.

9. Alimoglu MK, Yardım S, Uysal H. The effectiveness of TBL with real patients in neurology education in terms of knowledge retention, in-class engagement, and learner reactions. Adv Physiol Educ 2017 Mar 1;41(1):38-43.

10. Doshi NP. Effectiveness of team-based learning methodology in teaching transfusion medicine to medical undergraduates in third semester: A comparative study. Asian J Transfus Sci 2017 Jul-Dec;11(2):87-94.

11. Burgess A, Bleasel J, Haq I, Roberts C, Garsia R, Robertson T, et al. Team-based learning (TBL) in the medical curriculum: better than PBL? BMC Med Educ 2017 Dec 8;17(1):243. doi: 10.1186/s12909-017-1068-z.

12. Frame TR, Cailor SM, Gryka RJ, Chen AM, Kiersma ME, Sheppard L. Student perceptions of team-based learning vs traditional lecture-based learning. Am J Pharm Educ 2015 May 25;79(4):51. doi: 10.5688/ajpe79451. 